\title{
NOTA SOBRE ALGUNOS PRIMEROS POEMAS DE VICENTE HUIDOBRO TRADUCIDOS AL CATALAN
}

POR

MERLIN H. FORSTER

University of Texas at Austin

Los detalles de la producción poética del chileno Vicente Huidobro en francés durante 1917 y 1918, como también la introducción de su poesía y de su persona en España, forman parte de uno de los capítulos más importantes y complejos de la historia de los movimientos hispánicos de vanguardia ${ }^{1}$. La aparición de varios de los poemas franceses de Huidobro traducidos al catalán, pocos meses después de haberse publicado en París y antes de conocerse en castellano, es una dimensión de ese capítulo, que hasta ahora ha pasado inadvertida y que necesita, por consiguiente, un comentario detallado.

Como parte de una investigación iniciada hace algunos años sobre

${ }^{1}$ Son fundamentales para una documentación adecuada, dos estudios relativamente tempranos, el primero de Cedomil Goić, La poesía de Vicente Huidobro (Santiago de Chile: Universidad de Chile, 1956), y el segundo de David Bary, Huidobro, o la vocación poética (Granada: Universidad de Granada, 1963). También contribuyen en forma importante los libros más recientes de Enrique Caracciolo Trejo, La poesia de Vicente Huidobro y la vanguardia (Madrid: Gredos, 1974); Cecil G. Wood, The "creacionismo» of Vicente Huidobro (Fredrickton, New Jersey: York Press, 1978), y George Yúdice, Vicente Huidobro y la motivación del lenguaje (Buenos Aires: Galerna, 1978). Nicholas Hey ha preparado una fuente de consulta obligatoria en "Bibliografía de y sobre Vicente Huidobro», Revista Iberoamericana, núm. 91 (enero-junio de 1975), 293-353, y «Addenda a la bibliografía de y sobre Vicente Huidobro», Revista Iberoamericana, núms. 106-107 (enero-junio de 1979), 387-398. René de Costa ha reunido ensayos de diversos auto. res en dos tomos imprescindibles sobre Huidobro y la vanguardia: Huidobro y el creacionismo (Madrid: Taurus, 1975, 389 p.); Vicente Huidobro y la vanguardia (número especial de Revista Iberoamericana, núms. 106-107, enero-junio de 1979, 398 p.). 
las revistas y las figuras centrales de la vanguardia latinoamericana, repasé en la Bibliothèque Nationale en París los números de la revista literaria Nord-Sud (París, núms. 1-16, marzo de 1917 a octubre de 1918). Además de poder verificar los doce poemas con los cuales Huidobro contribuyó a la revista ${ }^{2}$, me encontré con una intrigante aseveración en cuanto a algunas revistas de vanguardia en España. El Cami, Arc Voltaïc y Trossos eran, se opinaba en un breve comentario, «jeunes revues qui prouvent l'effort que ce fait en ce moment en Espagne» (núm. 16, octubre de 1918). Más tarde pude consultar directamente muchos de los números de esas «revistas jóvenes» catalanas en la Biblioteca de Cataluña, en Barcelona. El carácter de las contribuciones publicadas, por ejemplo, el poema caligramístico «Planol», de J. Salvat Papaseit, en Arc Voltaïc (núm. 1, febrero de 1918), confirma la certeza de la pista ofrecida en Nord-Sud. Eran, en efecto, revistas de corta duración en las cuales se palpan el espíritu crítico del momento y una experimentación radical en la forma.

Más allá de la documentación de una vanguardia catalana, sin embargo, tiene relación directa con mis estudios latinoamericanos la publicación en El Camí (núm. 2, febrero de 1918) de cinco poemas de Huidobro («Torre Eiffel»; «Quatre poèmes»), traducidos al catalán por J. H. V. ${ }^{3}$ Otra vez, la conexión con Nord-Sud es necesaria, aun cuando no especificada por el traductor o el editor. Por ejemplo, la sección en la cual figuran los poemas de Huidobro lleva el título de «Poesía francesa», y el poeta se nombra como Vincent Huidobro (subrayado mío). Una ligera confrontación de textos revela que los cinco poemas traducidos son de dos números distintos de Nord-Sud: "Quatre poèmes» (núms. 4-5, juniojulio de 1917, pp. 20-21); «Tour Eiffel» (núms. 6-7, agosto-septiembre de 1917, pp. 24-25).

De acuerdo con sus distintas versiones y fechas de publicación, estos poemas con traducción catalana deben ser considerados en varios grupos. Los dos textos iniciales de "Quatre poèmes», por ejemplo, tienen tres versiones principales en dos lenguas diferentes ${ }^{4}$. Las versiones catalanas, reproducidas a continuación, representan una ampliación del cuadro:

${ }^{2}$ Véanse el recuento preciso y el estudio de estos textos franceses en Bary (pp. 67-87) y el cuidadoso estudio de Richard L. Admussen y René de Costa, "Huidobro, Reverdy, and the editio princeps of $E l$ espejo de agua», Comparative Literature, 24 (1972), 163-175.

${ }^{3}$ No he podido identificar al traductor más allá de estas iniciales.

${ }^{4}$ Admussen y De Costa, op. cit., establecen con cuidado los textos correspondientes en castellano y francés, y por eso reproduzco aquí solamente las traducciones al catalán. 
Les hores llisquen

Com gotes d'aigua sobre un vidre

Silenci de mija nit

La por

Es desenrotlla en l'aire

$\mathrm{O} ! \ldots$

Es una fulla

Pensem que la terra ha de finir

Tothom dorm

Un sospir

Dins la casa algú acaba de mórir.

Alguna cosa frega la paret

Una ànima se sent que ara vol nèixer

Cega

Sembla que algú cerqui una porta

Demà els ulls seràn oberts

Un soroll

No es troba

En la vida

De vegades hi ha un xic de sol

Ella vindrà

L'esperen.

Como indican Admussen y De Costa, estos dos poemas tienen versión primitiva en castellano en la editio princeps de 1916, con los títulos de «Nocturno» y «Alguien iba a nacer». Se eliminaron los títulos al traducirse los textos para Nord-Sud, y se introdujeron variantes de sintaxis y de puntuación. Las versiones francesas de Horizon Carré (1917) son las definitivas, en las cuales se ven los experimentos espaciales y tipográficos que se han identificado con esa etapa de la poesía de Huidobro. Las traducciones al catalán están hechas, obviamente, sobre los textos franceses intermedios de Nord-Sud, pues no corresponden a la versión inicial en castellano ni a la más evolucionada de Horizon Carré. Con todo, las traducciones catalanas anteceden la aparición de la segunda edición de 
Espejo de agua en Madrid, en 1918. Podemos representar esta complicada relación linguístico-bibliográfico-temporal así:

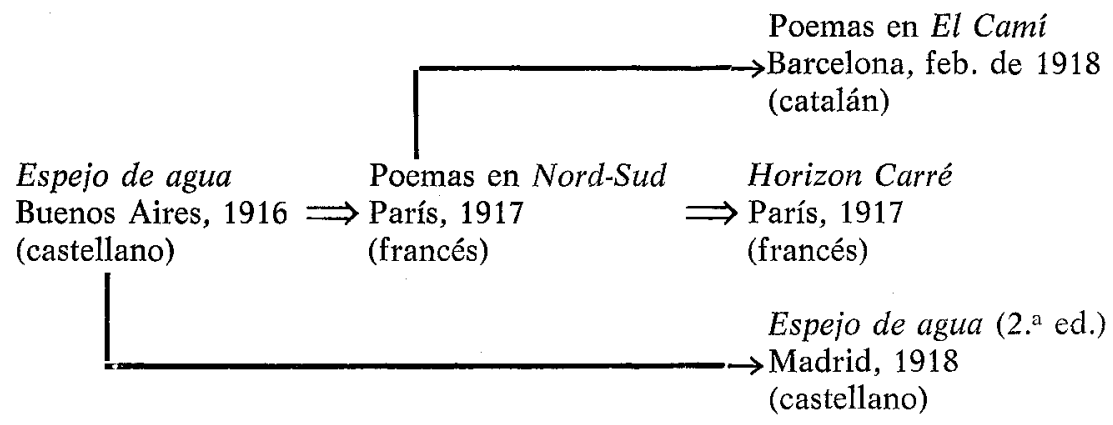

Una segunda agrupación se puede formar con los dos últimos textos de «Quatre poèmes». De nuevo, presentamos solamente las versiones catalanas:

\section{III}

Filla

En la vida

Esperen

Hi ha un camí

On moren les tardes

Algú ve.

IV

EL MIRALL

La meva faç

I al volant un xic d'aigua

El mirall

Una porta oberta

Que mostra una cambra semblant

Mico!

Perquè fas tu ço que jo faig

Jo espero darrera el mirall.

Estos poemas no formaban parte de Espejo de agua, y por eso su primera versión es la francesa de Nord-Sud. El breve texto III tampoco 
fue recogido en Horizon Carré ${ }^{5}$, y queda en su forma primitiva y reducida, sin la posible ampliación de una segunda versión. El texto IV lleva el título de «La Glace» en la original francesa de Nord-Sud, denominación reflejada exactamente en la catalana y cambiada a «Glace» en la definitiva francesa de Horizon Carré. De nuevo, podemos apreciar en el texto retocado las modificaciones de tipografía y de espacio visual que empezaban a caracterizar la poesía de Huidobro.

E1 texto denominado «Torre Eiffel» constituye una última categoría:

\section{Torre Eiffel}

Guitarra del cel

La teva telagrafia

Atrau els mots ${ }^{6}$

Com un roser les abelles

De nit la Sena

E1 seu corrent no mena

Torre Eiffel

Rusc dels mots

Tinter de mel

Aranya amb potes de filferro

que fa la seva tela amb núvols

Fillet mey

Per pujar a la Torre Eiffel

Cal muntar damunt una canço

Do

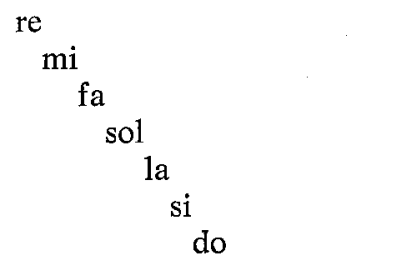

${ }^{5}$ En su recopilación Obras completas de Vicente Huidobro (Santiago de Chile: Andrés Bello, 1976), tomo I, pp. 616-621, Hugo Montes recoge una versión de este poema. Va bien la indicación al número de Nord-Sud (núms. 4-5, junio-julio de 1917), pero nos parece que el texto mismo se reproduce mal bajo el título de «Ou Sommes Nous».

${ }^{6}$ El texto publicado en El Camí reza «morts» aquí. Tiene que ser error de imprenta, porque el texto francés de Nord-Sud indica «mots» en este verso. 


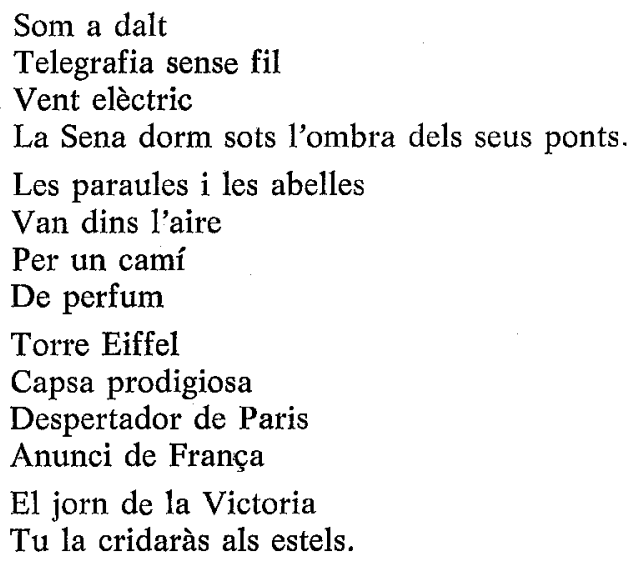

Se trata de otro poema compuesto por Huidobro directamente en francés, publicado primero en Nord-Sud y al año siguiente en Madrid como plaquette. La versión catalana sigue el texto primitivo en francés, que tiene solamente algunas de las innovaciones visibles en el texto final de 1918. El tema y las tonalidades de las versiones sucesivas son comparables: los valores sentimentales y comunicativos de la Torre se aprecian y se sube a la estructura de hierro en una canción para después contemplar el Sena dormido bajo sus puentes. Sin embargo, con excepción de la indicación transversal de la escala musical, hay bastante menos representación visual en la primera versión de esta «aranya amb potes de filferro», como también menos uso de los juegos de puntuación y tipografía que hemos considerado al comentar los otros textos.

Después de haber repasado brevemente algunos textos de Vicente Huidobro en catalán en función de sus contribuciones a Nord-Sud y otras publicaciones, ¿cuáles son las conclusiones principales que se pueden sacar? En primer término, parece que Huidobro llegó primero a España como poeta francés traducido al catalán. La aparición de las traducciones que aquí comentamos antecede a los libros más conocidos de Huidobro, publicados en Madrid en 1918 con poemas en francés y castellano, y le conecta desde Francia con un foco vanguardista peninsular antes de su muy comentada visita a Madrid.

En segundo término, este proceso mismo de traducción subraya la importancia de Barcelona y la zona catalana como vía de contacto entre 1a Península Ibérica y Europa, y en particular con Francia. En el caso de Huidobro, sin entrar en otros posibles ejemplos, el mundo literario de Barcelona se mostró estar más al tanto de las innovaciones del momento que el de Madrid. 